\title{
Improving the Temperature Sensitivity of Bitumen for Emergency Pavement Repair
}

\author{
Hayder Al Hawesah¹, Monower Sadique ${ }^{1}$, Clare Harris $^{1}$, Hassan Al Nageim¹ ${ }^{1}$ Karl Stopp², \\ Harry Pearl ${ }^{3}$, Ali Shubbar ${ }^{1,4^{*}}$ \\ ${ }^{1}$ School of Civil Engineering and Built Environment Liverpool John Moores University (LJMU), Henry Cotton Building, Webster Street, \\ Liverpool L3 2ET, UK \\ 2 STOPPTECH Ltd, The Mill, Pury Hill Business Park, Alderton Road, Towcester NN12 7LS, UK \\ ${ }^{3}$ Billian UK Limited, Butterthwaite Business Park, 1a, Butterthwaite Ln, Sheffield S35 9WA, UK \\ ${ }^{4}$ Department of Building and Construction Technical Engineering, College of Technical Engineering, The Islamic University, 54001 \\ Najaf, Iraq \\ * Corresponding author, e-mail: A.A.Shubbar@ljmu.ac.uk
}

Received: 13 April 2021, Accepted: 25 July 2021, Published online: 04 August 2021

\begin{abstract}
The quality of asphalt pavement maintenance depends on several important factors, including the selection of patching materials and choice of repair technique. Conventional hot mix plants operate to support large paving projects, and economy favors high-volume output. When repairs and maintenance are needed it can be challenging to maintain small quantities of hot bituminous mixtures at a sufficient temperature, especially in the case of winter maintenance and consequently the repair materials cannot be compacted to the desired level in some occasions. The temperature sensitivity plays a significant factor to understand the asphalt pavement failures and indicates how quickly asphalt properties change over time in terms of indices such as penetration index. Therefore, this research aims to develop a polymer-modified binder with reduced temperature sensitivity, and it can be used for hand-laid application in small quantities for emergency winter repair and maintenance. The results showed that the highest penetration index has been achieved by modifying bitumen with $20 \%$ rubber and $2 \%$ wax, which is reduced the temperature sensitivity by $168 \%$. Additionally, the Fourier Transform Infrared Spectroscopy (FTIR) test and X-Ray Diffraction (XRD) test were conducted to monitor the changes in the chemical composition and identify crystalline phases of polymer modified binder from the aspect of functional groups. It is indicated that the bitumen, rubber, and wax react chemically to build 3D networks that have an interlaced form in the bitumen matrix resulting in reduced temperature sensitivity of the polymer modified binder.
\end{abstract}

Keywords

polymer modified binder, temperature sensitivity, penetration index, FTIR, XRD

\section{Introduction}

Producing high-quality asphalt materials for low-volume hand-laid applications for pothole patching and utility cut repairs has always presented a challenge. The commonest used material in pothole repair is hot-mix asphalt (HMA). There is a main drawback of HMA as it is produced in batches of two to three tonnes, however, the average patch requires only a small amount of asphalt [1]. When keeping the HMA at high temperature for long times during the process of mixing, transportation and storage, the bitumen ages and its viscosity and softening point are increased leading to fretting and/or cracking [2]. Also, the temperature of HMA drops during transportation, especially for remote maintenance during winter. This reduction in temperature not only reduces the compressibility of the mixture (high air void content) but also weakens the joint between the old surface and the new patching materials by triggering moisture ingress. Moreover, based on two years field survey, they indicated that patching material cost only a small portion of the total cost for pothole repair, therefore, expensive materials can provide longer repair longevity will be cost-effective [3].

Over recent decades, some polymeric materials have been developed to improve asphalt patching repair materials, but these were relatively expensive making them suitable only for special applications. Modifying bitumen with some additive materials can improve bitumen 
characteristics such as the adhesion to aggregate and workability and thus improving the properties of the final asphalt mixture [4]. Additives are used to delay the deteriorations and extend the service life of the pavements [4].

The temperature sensitivity of asphalt binder plays a significant factor to understand the asphalt pavement failures, especially on the asphalt aggregate adhesion [5], as well as it is related to asphalt mixtures ability to resist permanent deformation [6]. The temperature sensitivity indicates how quickly asphalt properties change over time in terms of indices such as penetration index (PI). All asphalt binders own similar basic thermoplastic properties as being softer when heated and stiffer when cooled [7]. Normal asphalt binder has PI ranging between $(-2$ and +2$)$. Asphalt binder has low sensitivity to temperature when PI values increased more than +2 , while the asphalt binder is extremely sensitive to high temperature when PI values less than -2 [8].

Using polymer in modifying asphalt has been considered as a great option to produce mixtures that can resist both rutting and cracking, however from the economic perspective it is relatively expensive. Therefore, the use of recycled polymer such as crumb rubber offers an inexpensive alternative [9]. For example, Kisgyörgy et al. [10] concluded that adding rubber to asphalt binder improved the rutting and fatigue resistances of the asphalt mixture which extend the lifecycle and result in lower maintenance costs. Rubberized binders have improved asphalt pavement's quality, increased rutting and cracking resistance and eventually reduced maintenance costs [11]. Critical evaluation of several previous research papers showed that the low content of rubber (around 4\%) has almost no significant effect on the mechanical properties and the performance of the asphalt mixtures, more than $20 \%$ was also found to be inappropriate [11]. Moreover, from the angle of visco-flow characteristics and viscosity, it is suggested to use $15 \%-25 \%$ of crumb rubber at $180{ }^{\circ} \mathrm{C}$ of treatment temperature and a treatment time of 90 minutes [12]. However, rubberized binders may be attributed to the weak compatibility between rubber and bitumen, which is demonstrated by its propensity to separate during transportation to the paving site or during high-temperature static storage [13]. Hence, transportation and temperature can be considered very important factors because they impact on the performance of the pavement. Therefore, adding wax to rubberized binder may tackle this problem which reduce the temperature construction and improve the temperature sensitivity of binder $[14,15]$.
Wax (Sasobit $\AA$ ) is an additive to bitumen to improve its workability and durability. Sasobit ${ }^{\circledR}$ additive could reduce the mixing and compaction temperatures of rubberized asphalt mixtures and extend the long-term performance of the pavement [16]. At temperatures under $100{ }^{\circ} \mathrm{C}$, Sasobit ${ }^{\circledR}$ seemingly forms a structure of crystalline lattice in the binder that results in increased rutting resistance at service temperatures leading to improved stability [17]. Furthermore, Sasobit ${ }^{\circledR}$ plays as a flow-improver reducing the binder viscosity and thus enabling lower mixing and compacting temperatures [14]. Recent studies have demonstrated that adding $1 \%-3 \%$ of Sasobit ${ }^{\circledR}$ to the asphalt binder lowers the binder viscosity, making it easier to be mixed and handled at lower temperatures compared with unmodified asphalt binder [18]. They also recommended that the best percentage of Sasobit ${ }^{\circledR}$ to be added to the asphalt binder is $2 \%$ while higher percentages have negatively affected the performance of asphalt against thermal cracking [18].

From the literature, it can be concluded that rubber and wax have a strong influence on the properties of the binder, as well as the mixture. These materials are expected to improve the temperature sensitivity of asphalt binder, workability and durability of asphalt mixtures, especially mixing rubber with wax, which will improve the workability and reduce the rolling temperature. Therefore, the main objective of this research is to develop a polymer-modified binder from a combination of rubber and wax with reduced temperature sensitivity for handlaid application in small quantities for emergency winter repair and maintenance.

\section{Materials and Experimental methods}

Based on the previous studies detailed, the neat bitumen binder samples were modified with rubber and wax by adding the desired percent by weight of additives to the binder (neat bitumen), in wet process the asphalt modifier (Rubber and/or Sasobit) was added gradually into the bitumen at $180{ }^{\circ} \mathrm{C}$ and $800 \mathrm{rpm}$, for 90 minutes in shear. Table 1 shows the initial physical properties of the candidate binder and additives. The grade of the bitumen used in this research was 100/150 according to BS EN 12591 [19].

In order to investigate the individual influence of rubber and wax on binder (neat bitumen), three types of mixes containing different workable ranges of these modifiers in the binary blend were tested, in three replicates, as shown in Table 2. 
Fig. 1 illustrates the flowchart to show the methods, materials and tests performed to evaluate the physical properties of the modified binder. Firstly, the asphalt binder (neat bitumen) was heated in an oven at $180^{\circ} \mathrm{C}$ for 1 hour.

Table 1 Initial physical properties of candidate binder and additives

\begin{tabular}{lcc}
\hline Materials & Property & Value \\
\hline \multirow{3}{*}{ Bitumen 100/150 } & Penetration (mm) at $25^{\circ} \mathrm{C}$ & 110 \\
& The softening point & 43.5 \\
& Density g/ $\mathrm{cm}^{3}$ & 1.05 \\
Wax (Sasobit $\left.{ }^{\circledR}\right)$ & Flashpoint ${ }^{\circ} \mathrm{C}$ & 285 \\
& Melting point ${ }^{\circ} \mathrm{C}$ & $75-115$ \\
Rubber & Density g/cm & 0.9 \\
& Particle size $\left(\mathrm{mm}^{3}\right.$ & $0.4-0.45$ \\
\hline
\end{tabular}

Table 2 Experimental scheme to investigate the influence of candidate additives on binder

\begin{tabular}{lcc}
\multicolumn{3}{c}{ additives on binder } \\
\hline Mixtures & $\begin{array}{c}\text { Percentages by weight } \\
\text { of neat bitumen }\end{array}$ & \\
& Rubber $\%$ & Wax $\%$ \\
Influence of & In the range of $0-30 \%$ & - \\
rubber & with 5\% increment & In the range of $0-4 \%$ \\
Influence of wax & - & with $1 \%$ increment \\
\hline
\end{tabular}

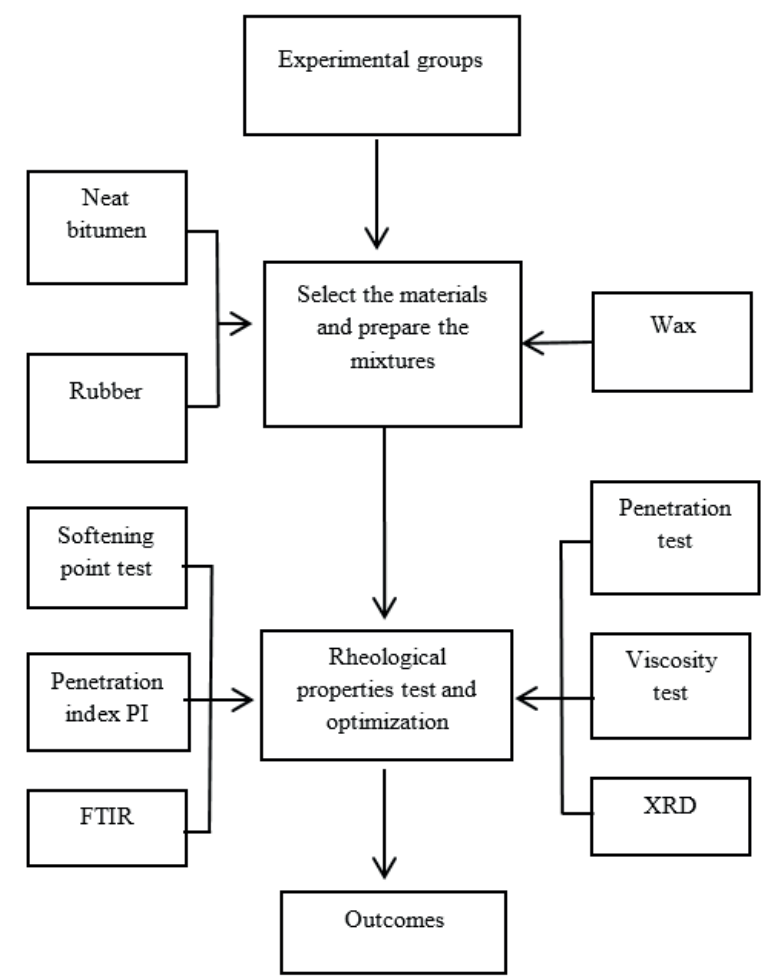

Fig. 1 Flowchart showing the methods, materials and tests performed to evaluate the physical, mechanical and durability properties of the developed binder
Then, the modifier materials (rubber and wax) were blended with bitumen at $180^{\circ} \mathrm{C}$ and $2000 \mathrm{rpm}$, for $90 \mathrm{~min}$. Penetration test was conducted in three replicates according to BS EN 1426 [20]. The penetration test is a commonly used method to assess the consistency of a bituminous material at a specific temperature. The standard test for softening point of bituminous materials is Ring and Ball method that has been conducted in three replicates according to BS EN 1427 [21]. The softening point indicates the temperature at which bitumen starts to display fluidity [22]. As it is known, the softening point has a direct relationship with asphalt deformation; the higher softening point the more deformation resistance [23]. The Penetration index (PI) is the measure of temperature sensitivity of bitumen and stiffness of asphalt. Low temperature sensitivity is a reflection of increased resistance against thermal cracking and permanent deformation [24]. Thus, asphalt mixture containing binder with high PI have greater resistance to low-temperature permanent and deformation cracking [24].

The calculation of the PI is based on values of penetration and softening point according to [25]. PI was calculated by using the equation provided below:

$$
P I=(1952-500 \log P-20 S P) /(50 \log P-S P-120),
$$

where:

$S P$ : softening temperature in degrees Celsius.

$\log P$ : common $\operatorname{logarithm}$ of penetration at $25^{\circ} \mathrm{C}$

Viscosity can be defined as the resistance to the flow of a fluid. Considering the standard test temperature used by $\mathrm{Li}$ et al. [12], the test was performed in three replicates at a mixing temperature of $180^{\circ} \mathrm{C}$ for polymer modified binder. A Brookfield DV-II+ Pro Viscometer rotational viscometer was used according to BS EN 13302 [26] at $180{ }^{\circ} \mathrm{C}$.

Physical and chemical asphalt binder properties can be described based on FTIR spectra [27]. FTIR spectroscopy is the most frequently used tool to observe the changes in the chemical structure of bitumen after ageing and measure the oxidation products. FTIR gives precise information regarding oxygenation rate, aliphaticity, and aromaticity [28]. The FTIR spectroscopy was conducted using the instrument: Perkin-Elmer Spectrum BX series Fourier transform infrared spectrometer (FT-IR), equipped with a Miracle ATR accessory. In this research, the FTIR was employed on the neat bitumen and polymer modified binder. $\mathrm{X}$-Ray Diffraction (XRD) is a non-destructive and multipurpose analysis technique used to distinguish crystalline phases in the materials and to investigate the structural 
properties of these phases. The XRD test was conducted using the instrument Rigaku mini-flex diffractometer (mini-flex goniometer), CuK X-ray radiation $(30 \mathrm{kV}$ voltage and $15 \mathrm{~mA}$ current at scanning speed of $2.0 \mathrm{deg} . / \mathrm{min}$ in continuous scan mode) and scanning range (2 $\theta)$ of $5-60^{\circ}$. $\mathrm{XRD}$ is a commonly used tool to determine the crystallite parameters of modified binder; it offers quantitative intensity curves according to the peak intensity and position of the structural parameters in the binder sample [29].

\section{Results and discussions}

\subsection{Influence of rubber on binder}

The influence of rubber content on binder PI and dynamic viscosity is illustrated in Figs. 2 and 3 respectively. The penetration value decreases from 110 to $25 \mathrm{~mm}$ and the softening point value rises by $61 \%$ as rubber content increases from $0 \%$ up to $30 \%$ in the mixture (Figs. 2(a), 2(b)), these findings came in accordance with Mashaan et al. [30] studies. The PI was considerably increased by the addition of

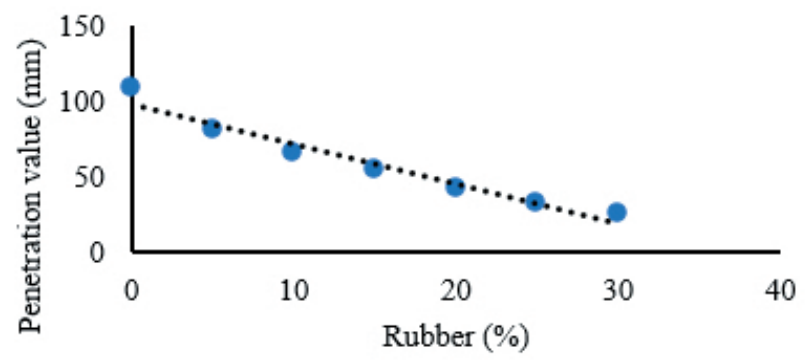

(a) Penetration

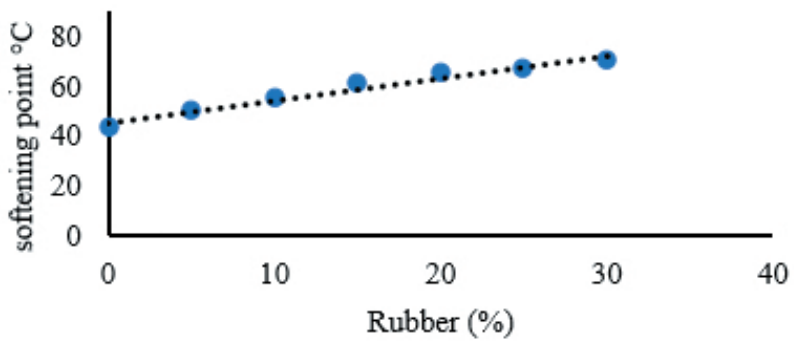

(b) Softening point

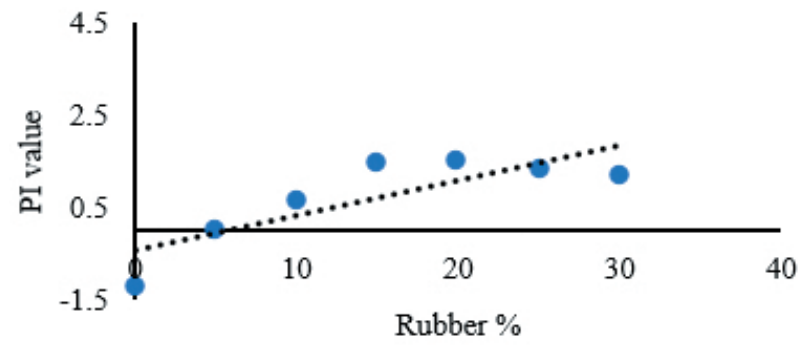

(c) PI

Fig. 2 Influence of rubber on bitumen, a) penetration test, b) softening point test, c) penetration index PI

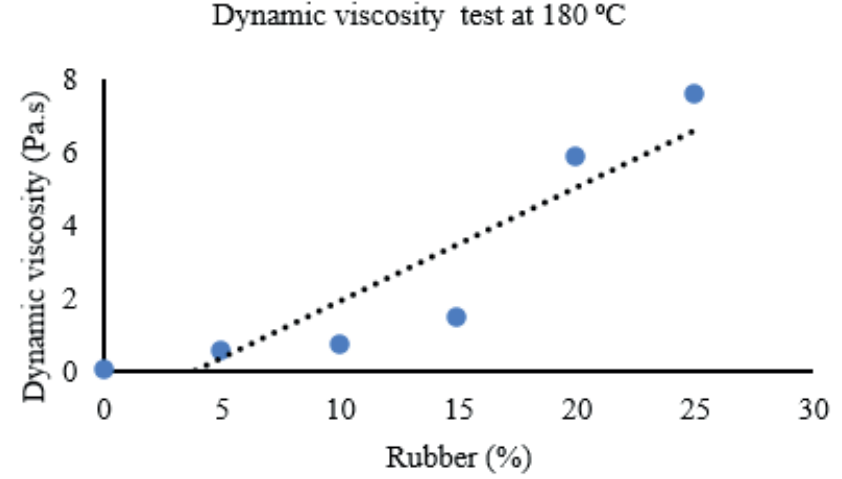

Fig. 3 Influence of rubber on dynamic viscosity of bitumen

rubber, up to positive values of about 1.50 when adding $20 \%$ rubber, as shown in Fig. 2(c), which consequently improved the temperature sensitivity of the rubberized binder. Indeed, adding rubber enhanced the performance properties of asphalt mixture in terms of deformation resistance during construction and traffic loads [9]. Moreover, a binder with a higher PI has a higher resistance to low temperature cracking and permanent deformation, as reported by many studies [24, 31]. To maximize the PI of rubberized binder, the optimum dose was found to be $20 \%$ in this research, which was in agreement with the findings of Porto et al. [11]. The positive correlation between rubber content and viscosity is evident in Fig. 3. Significantly, sharp increases (from 1.52 to $7.58 \mathrm{~Pa} . \mathrm{s}$ ) in viscosity were recorded above $15 \%$ up to $25 \%$ rubber content. This could happen because the rubber absorbs the light component of the bitumen, resulting in variation of the binder component that increases binder viscosity in the rubber-modified binder (RMB) system. The increased viscosity leads to an increase in binder film thickness around the aggregate because of the gel structure estimated by the RMB, improving the adhesion and cohesion of the asphalt mixture [32].

Significant improvements in terms of aging and creep stiffness, as well as lower energy requirement, were reported by Wang et al. when the dosage of rubber was in the range of $15 \%-20 \%$ [33]. Generally, the larger the dosage of crumb rubber, the greater the viscosity of RMB thus improving the properties of the binder at high temperature, nevertheless, an extreme dosage of crumb rubber perhaps result in the weakness of asphalt mixture with inferior end properties at low winter temperatures. Considering all the factors above and the results for PI and viscosity, the optimum rubber dosage was observed to be $20 \%$ in bitumen modified, a level that is expected to increase the workability and durability of the proposed asphalt mixture. 


\subsection{Influence of wax on binder}

The influence of wax concentration on binder PI and dynamic viscosity is illustrated in Figs. 4 and 5, respectively. Varying the wax concentration was shown to influence the penetration and softening point of the binder as well as the PI in a similar way to varying the rubber content. The explanation for this might be that when the wax cools and crystallizes it forms a uniform network structure in the modified binder [14]. Furthermore, at temperatures under $100{ }^{\circ} \mathrm{C}$, wax seemingly forms a crystalline lattice structure in the binder that results in increased rutting resistance at service temperatures leading to more stability [17]. Fig. 4(c) illustrates that optimum PI was identified when the wax content was around $2 \%$ when the PI recorded 2.165. Previous researchers have recommended the addition rate of wax to be in the range of $1 \%-3 \%$ by mass of the binder [34]. Others have reported that using more than $4 \%$ wax has a harmful impact, causing cracking of asphalt mix at low temperatures [14]. Additionally, Ghuzlan and Al Assi [18] pointed out that the optimum percentage of wax to

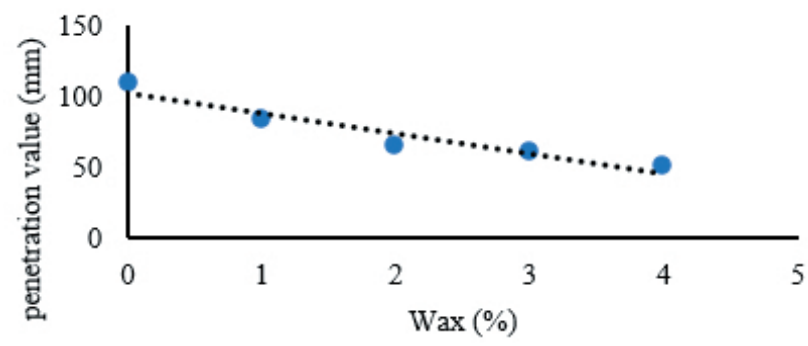

(a) Penetration

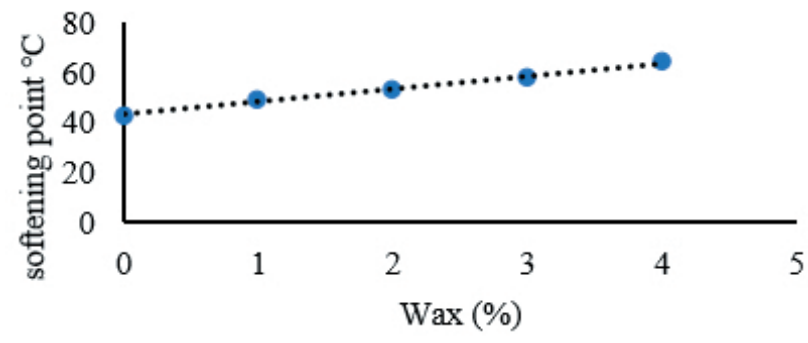

(b) Softening point

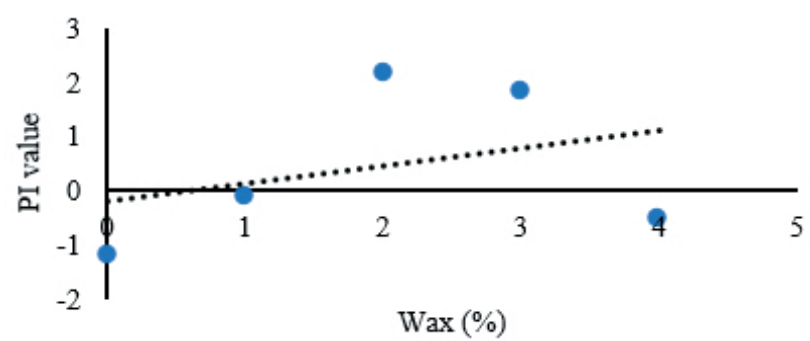

(c) PI

Fig. 4 Influence of wax on bitumen, a) penetration test, b) softening point test, c) penetration index $\mathrm{PI}$

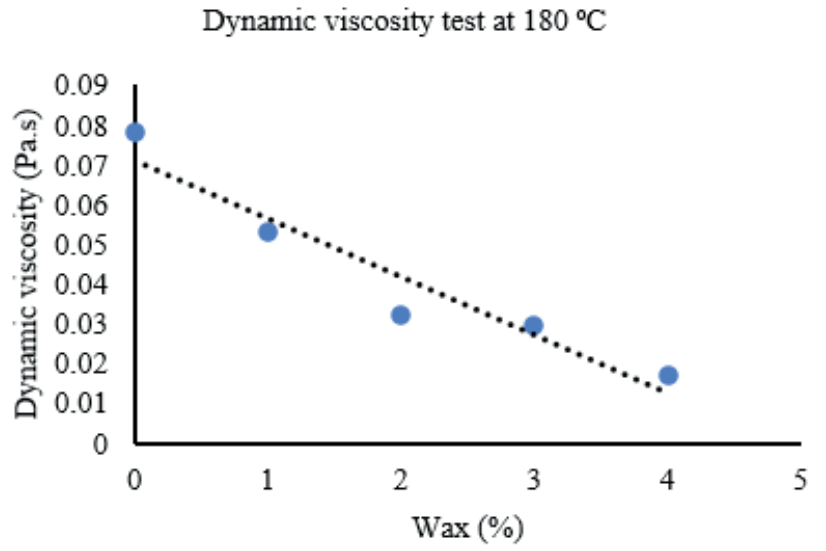

Fig. 5 Influence of wax on dynamic viscosity of the bitumen

be added to the asphalt binder is $2 \%$, and higher percentages negatively affect the performance of asphalt. Thus, with the addition of $2 \%$ wax, the modified binder is expected to be less susceptible to temperature changes. Hainin et al. [14] found that the network of a crystalline structure formed in the wax-modified binder reduces temperature sensitivity and increases the elasticity of the binder. As can be seen in Fig. 5, increasing the wax content of bitumen reduced its viscosity. This observation might partly be explained by assuming that some parts of the wax dissolved in bitumen due to that most waxes have low molecular content and/or oil-based molecules [15]. Furthermore, wax forms a homogeneous solution with bitumen resulting in a significant reduction in its viscosity [15].

The melting point of wax is around $100{ }^{\circ} \mathrm{C}$ and it is completely dissolved in bitumen at temperatures higher than $115^{\circ} \mathrm{C}$ [17]. Hainin et al. [14] showed that wax affects the viscoelastic properties of binder differently depending on the temperature. It can decrease the viscosity of binder at high service temperatures (around $135^{\circ} \mathrm{C}$ ), whereas it has the opposite effect at low temperatures (around $80^{\circ} \mathrm{C}$ ) and increases the viscosity of virgin bitumen [14]. Thus, adding wax to bitumen will improve the viscosity (reduced viscosity) during mixing and decreased the construction temperatures.

\subsection{Influence of wax on binder modified with optimum rubber content}

Based on the PI results, the optimum rubber and wax contents were observed to be $20 \%$ and $2 \%$ respectively. Indeed, wax reduces the risk of compaction failures, especially when using very hard and highly viscous bitumen such as a rubber-bitumen system [14]. In general, high viscosity value leads to high mixing and compaction temperatures and that perhaps results in an increase of the energy 
consumption [35] and result in loss of modifying properties such as temperature sensitivity [36]. Therefore, with the aim of further enhancement in terms of PI and viscosity, a ternary blended binder through incorporating wax in the binder containing optimum level of rubber (20\%) was investigated. The results in Fig. 6(a) illustrate that adding wax to the rubberized binder increased the penetration slightly. This means that the hardness of rubber asphalt was slightly changed towards a softer grade. However, increasing the wax content (from 1-4\%) the increased softening point by $23 \%$ as illustrated in Fig. 6(b). The chemical composition of wax is described as fine crystalline materials in long-chain hydrocarbons [14]. This structure means that wax can adsorb saturated components (mostly waxbased or oil-based molecules) with a similar structure in a rubber-bitumen system at high temperatures [15]. When the temperature decreases, wax and saturated components crystallize together and form a stable crystal structure, which can improve the softening point of rubberized asphalt [15]. Significantly, the results displayed in Fig. 6(c)

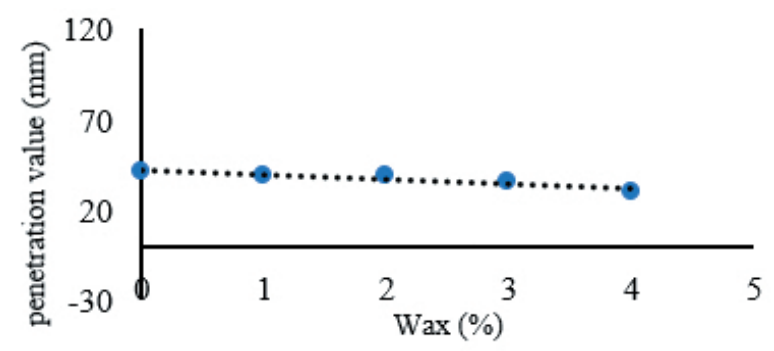

(a) Penetration

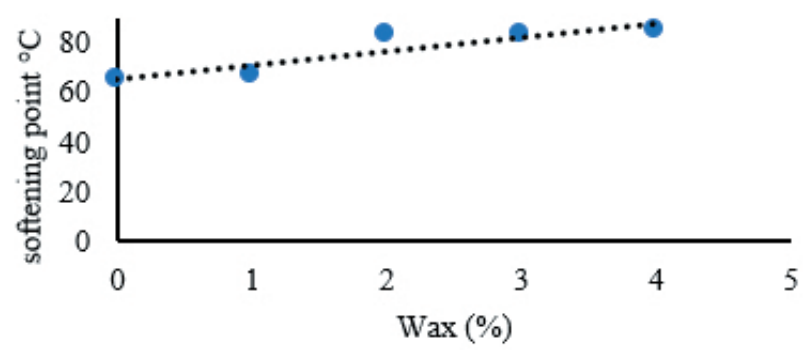

(b) Softening point

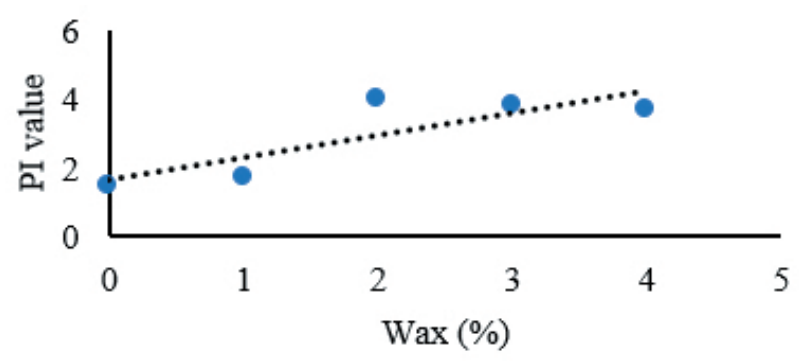

(c) PI

Fig. 6 Influence of wax on binder modified with $20 \%$ rubber, a) penetration test, b) softening point test, c) penetration index PI showed that adding 2\% wax to bitumen modified with $20 \%$ rubber considerably increased the PI value compared with the PI of solo and binary blends; the significant increase was around $168 \%$ as shown in Fig. 7.

However, reduction in viscosity associated with increasing wax content in a ternary blend (Fig. 8), this was in accordance with the findings in the case of a binary blend in Fig. 5. This can be explained by the ability of the wax to adsorb saturated components in the rubber-bitumen binder [15]. The effect of the wax follows two different trends based on temperature, decreasing the viscosity at high temperatures while increasing the viscosity at low temperatures [14].

From the findings presented, this ternary blended binder showed improved rheological properties of asphalt binder. The PI value indicates the temperature sensitivity; thus, the higher PI value provided by the ternary blended binder containing $20 \%$ rubber and $2 \%$ wax showed low

Dynamic viscosity at $180^{\circ} \mathrm{C}$

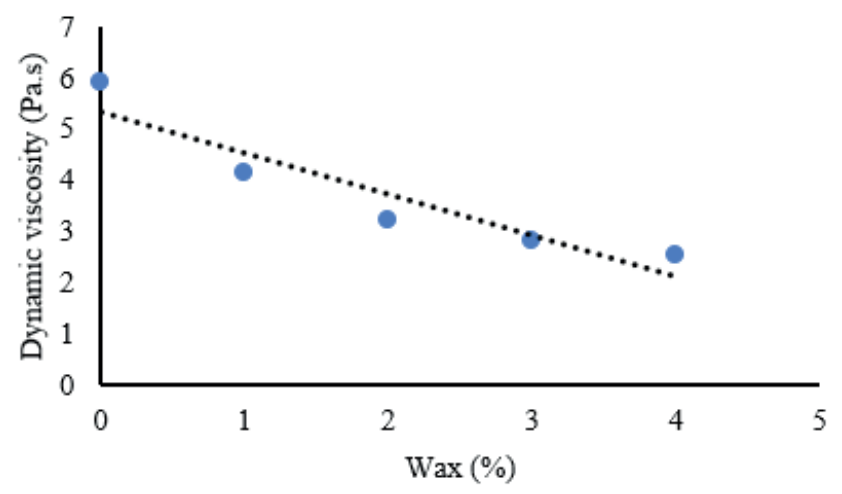

Fig. 7 Individual and combined influence of additives on binder PI

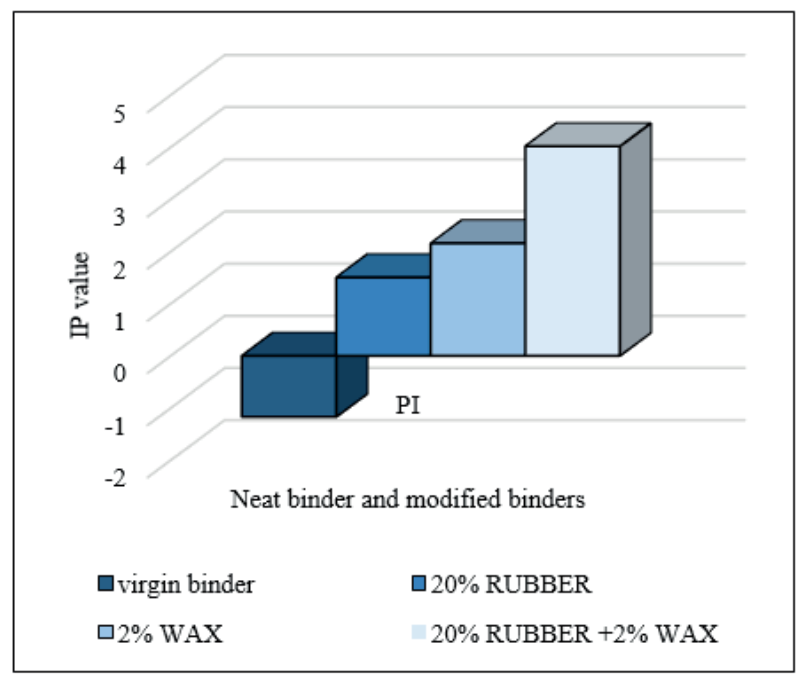

Fig. 8 Influence of wax on dynamic viscosity of bitumen modified with $20 \%$ rubber 
sensitive to temperature, which is expected to overcome the problem related to patching materials transportation. Asphalt mixtures containing bitumen with higher PI have a higher resistance to low temperature cracking and permanent deformation [24, 31]. Besides, wax allows producing rubber modified asphalt mixes at standard temperatures. This means the high melting temperature can be prevented, thereby emissions are reduced, binder aging is avoided, resulting in a huge contribution to environmental protection and eventually occupational health and safety. An additional benefit of the wax is that it improves the workability and compacting properties of asphalt mixtures.

\subsection{FTRI analysis}

FTIR spectra results could demonstrate that different chemical and physical asphalt binder properties, also it can recognize the linear combinations [27]. According to Fig. 9, the polymer modified binder and the neat bitumen both have almost similar chemical groups, including the asymmetrical stretch (peaks 600 to $1700 \mathrm{~cm}^{-1}$ ) and the symmetric (peaks 2850 to $2950 \mathrm{~cm}^{-1}$ ). However, polymer modified binder, as was expected, has additional peaks 1540 $\mathrm{cm}^{-1}$ and $1576 \mathrm{~cm}^{-1}$ which corresponded to $\mathrm{CH} 2$ and $\mathrm{C}=\mathrm{O}$ respectively, compared with the peaks presented for the neat bitumen. This inducted a chemical reaction between the compounds in the polymer modified binder [27,37].

Based on modified binder peak at $1580 \mathrm{~cm} 1$ which is aromatics [37] and corresponding to $\mathrm{C}=\mathrm{C}$. This result presented to concluded that adding wax and rubber to neat bitumen increases the aromatic content significantly. Lushinga et al. [28], have concluded that the higher content of aromatic components increases the resistance to

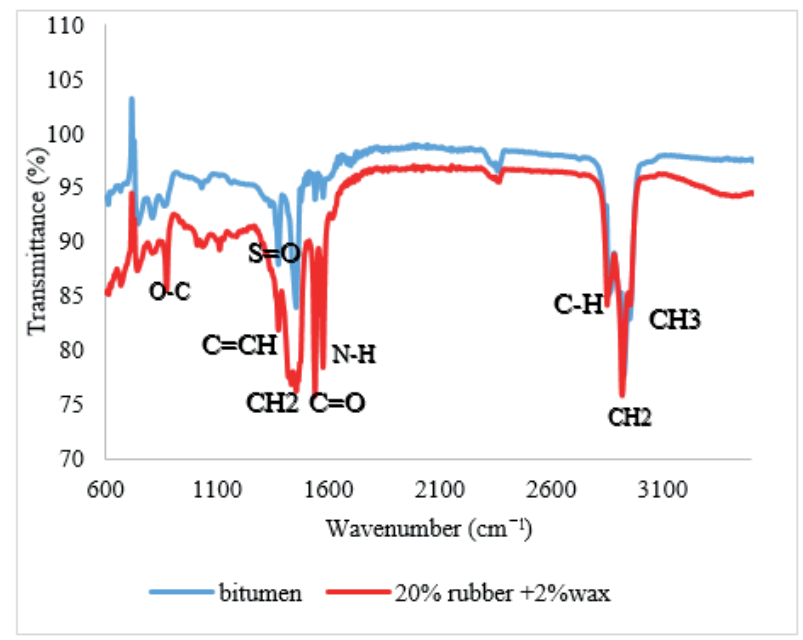

Fig. 9 FTIR for the binder modified with $20 \%$ rubber and $2 \%$ wax crack at low temperatures. Therefore, the high aromatic content improves low-temperature cracking performance and that inducted the binder has low temperature sensitivity $[24,31]$. Furthermore, a binder with high aromatic content improves the asphalt mixture performance in terms of water resistance and fatigue life. Furthermore, the spectra of modified binder showed a couple of strong sharp peaks in the range between 1500 and $1600 \mathrm{~cm}^{-1}$. The peaks intensity is sharp and thus it can be directly assigned to $\mathrm{N}-\mathrm{H}$ stretch. These peaks show the nitrogen presence as primary amines in crumb rubber [37]. However, using crumb rubber as polymer modifier binder the spectra indicate the presence of N-H stretch in the region 3280 and $3320 \mathrm{~cm}^{-1}$ as less intense [37], hence, the results inducted that this peak has been vanished and that could be explained due to adding wax to polymer modified with rubber showed a chemical reaction between wax and rubber [38].

The wavenumber ranges of $1030 \mathrm{~cm}^{-1}$ characterize the functional class of sulfoxide $(\mathrm{S}=\mathrm{O})$, the sulfoxide here expected from the rubber. The sulfoxide content in the rubber usually in the range $1-2 \%$ regardless of whether it is from a car or truck tire [32], as adding wax to polymer RMB did not show any increase in the sulfoxide [38]. Additionally, the wavenumber range of 2800 and $3000 \mathrm{~cm} 1$ which are symmetric in bitumen and polymer modified binder represent the functional class of aliphatic C-H stretch [37]. According to [39] the better asphalt binder has the most flexural peaks in the wavenumber range of 400-1500 $\mathrm{cm}^{-1}$ based on the FTIR test [39]. Here, among compounds for neat bitumen and polymer modified binder, the polymer modified binder has the most flexural peaks in the wavenumber range of $1355-1588 \mathrm{~cm}^{-1}$. Hence, polymer modified binder has a better performance than the neat bitumen.

\subsection{X-ray diffraction (XRD) analysis}

Fig. 10 shows the X-ray diffraction for polymer modified binder in comparison with the neat bitumen. As stated previously, the XRD method is used to chemically analyze bitumen specimens using centroid peak, peak area, and peak intensity.

The response of XRD of various compounds follows an identical pattern; and thus, the centroid peak and peak area are different for the neat bitumen and polymer modified binder and the peak intensity values are different. The wide band of 2-theta between 10 and 29 shows that the structure is amorphous and crystallized [40]. 


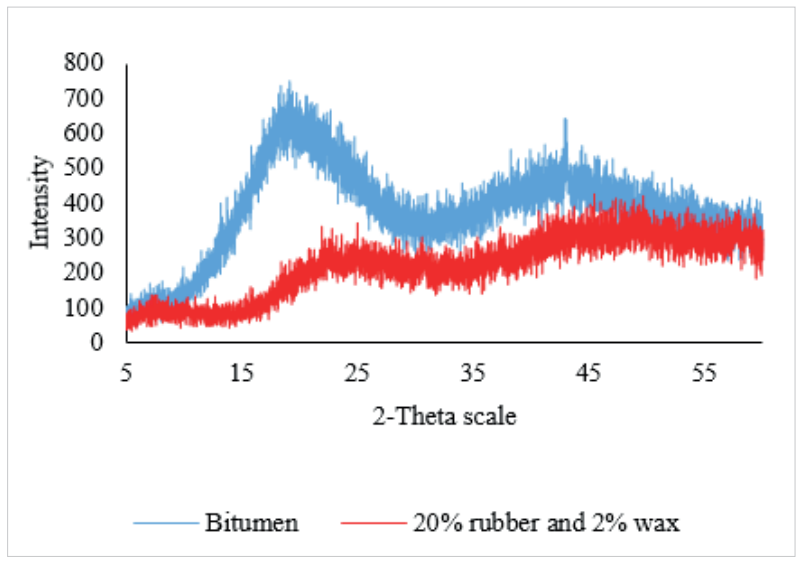

Fig. 10 Comparative XRD analysis of binders

According to Fig. 10, the polymer modified binder has lower peak intensity compared to the neat bitumen. Hence, adding rubber and wax to neat bitumen declined the peak intensity considerably, and improved structure crystallinity. This is indicated that the bitumen, rubber, and wax react chemically. Furthermore, the peak intensity indicates the relative strength of diffraction. Lower peak intensity results in less diffraction and improved low temperature cracking and temperature sensitivity [39]. The addition of $2 \%$ of wax to binder modified with $20 \%$ rubber builds 3D networks that have an interlaced form in the bitumen matrix [39] as the wax has crystallized its forms resulting in improved temperature sensitivity [14]. Based on the XRD test, when the peak intensity value decreased the temperature sensitivity decreased as well [40]. Concerning the presented results, the polymer modified binder has a better performance than the neat bitumen, which is confirmed by the results of PI and FTIR tests.

\section{Conclusions}

The work presented in this paper shows the preliminary results on developing a binder with minimal temperature sensitivity and enhanced viscoelastic properties

\section{References}

[1] Saeed, A., Hammons, M. I. "Airfield Repairs in Austere Locations", Applied Research Associates, Tyndall Air Force Base, FL, USA, Rep. AFRL-RX-TY-TP-2009-4553, 2009.

[2] Read, J., Whiteoak, D., Hunter, R. "Shell bitumen handbook", 5th ed., Thomas Telford Publishing, London, UK, 2003.

[3] Dong, Q., Huang, B., Zhao, S. "Field and laboratory evaluation of winter season pavement pothole patching materials", International Journal of Pavement Engineering, 15(4), pp. 279-289, 2014. https://doi.org/10.1080/10298436.2013.814772 for hand-laid application in low volumes for emergency repair. A series of experiments were performed to assess the temperature sensitivity of the modified binder through measuring the PI, FTIR and XRD of the modified binder in addition to analytical analysis. The results of binder tests showed that:

- Modify the binder with rubber and wax decreases the penetration and increases the softening point. This suggested that the modified bituminous binder is more resistant to flow and stiffer compared to neat bitumen.

- The effect of the rubber content was very noticeable when mixed with bitumen, in comparison to the other additives. Bitumen modified with $20 \%$ rubber resulted in high PI value; thus, $20 \%$ rubber was the optimal amount compared to the other proportions tested.

- Adding $2 \%$ wax to bitumen modified with $20 \%$ rubber was observed to have a significant impact on the penetration and softening point of the binder, resulting in greater PI value improving the rheology of the binder at ambient and melting temperatures. Thus, the resultant binder can be used for patching materials that is expected to overcome the problem related to transportation.

- Moreover, the addition of rubber to the neat bitumen has considerably increased the viscosity; conversely, adding wax reduced the viscosity value. Indeed, wax decreases the viscosity at high temperatures while increases the viscosity at low temperatures thus preventing binder aging. In addition, the high mixing temperature can be avoided thus reducing emissions representing a huge contribution to environmental protection and occupational health and safety.

- Based on the FTIR and XRD analysis, it is indicated that the bitumen, rubber, and wax react chemically to build 3D networks that have an interlaced form in the bitumen matrix resulting in reduced temperature sensitivity of the polymer modified binder.

[4] Hamedi, G. H., Sahraei, A., Hadizadeh Pirbasti, M. "An Experimental Investigation into the Effect of Asphalt Binder Modified with SBR Polymer on the Moisture Susceptibility of Asphalt Mixtures", Periodica Polytechnica Civil Engineering, 65(2), pp. 546-555, 2021. https://doi.org/10.3311/PPci.16691

[5] Wu, S., Xiao, Y., Liu, Q., Cao, T. "Temperature sensitivity of Asphalt-Aggregate Adhesion via Dynamic Mechanical Analysis", Key Engineering Materials, 385-387, pp. 473-476, 2008. https://oi.org/10.4028/www.scientific.net/KEM.385-387.473 
[6] Wang, L., Wei, J., Zhang, Y. "Development of alternative parameters to evaluate the temperature susceptibility of asphalt binders", International Journal of Pavement Research and Technology, 2(2), pp. 75-81, 2009.

[7] Kishchynskyi, S., Nagaychuk, V., Bezuglyi, A. "Improving Quality and Durability of Bitumen and Asphalt Concrete by Modification Using Recycled Polyethylene Based Polymer Composition", Procedia Engineering, 143, pp. 119-127, 2016.

https://doi.org/10.1016/j.proeng.2016.06.016

[8] Abed, Y. H., Al-Haddad, A. H. A. "Temperature Susceptibility of Modified Asphalt Binders", IOP Conference Series: Materials Science and Engineering, 671, Article number: 012121, 2020. https://doi.org/10.1088/1757-899X/671/1/012121

[9] Mashaan, N. S., Ali, A. H., Karim, M. R., Abdelaziz, M. "A Review on Using Crumb Rubber in Reinforcement of Asphalt Pavement", The Scientific World Journal, 2014, Article ID 214612, 2014. https://doi.org/10.1155/2014/214612

[10] Kisgyörgy, L., Tóth, C., Geiger, A. "Elastic modulus of asphalt with chemically stabilized rubber bitumen, Elastic", Gradjevinar, 68(7), pp. 533-541, 2016. https://doi.org/10.14256/JCE.1451.2015

[11] Porto, M., Caputo, P., Loise, V., Eskandarsefat, S., Teltayev, B., Rossi, C. O. "Bitumen and Bitumen Modification: A Review on Latest Advances", Applied Sciences, 9(4), Article number: 742, 2019. https://doi.org/10.3390/app9040742

[12] Li, P., Jiang, X., Ding, Z., Zhao, J., Shen, M. "Analysis of viscosity and composition properties for crumb rubber modified asphalt", Construction and Building Materials, 169, pp. 638-647, 2018. https://doi.org/10.1016/j.conbuildmat.2018.02.174

[13] Behnood, A. "Application of rejuvenators to improve the rheological and mechanical properties of asphalt binders and mixtures: A review", Journal of Cleaner Production, 231, pp. 171-182, 2019. https://doi.org/10.1016/j.jclepro.2019.05.209

[14] Hainin, M. R., Aziz, M. M. A., Feizabadi, S. M., Jaya, R. P., Hassan, N. A., Jakarni, F. M. "An Overall Review: Modified Asphalt Binder Containing Sasobit in Warm-Mix Asphalt Technology", Jurnal Teknologi, 73(4), pp. 1-6, 2015. https://doi.org/10.11113/jt.v73.4275

[15] Wang, T., Yang, R., Li, A., Chen, L., Zhou, B. "Effects of Sasobit and its adding process on the performance of rubber asphalt", Chemical Engineering Transactions, 51, pp. 181-186, 2016. https://doi.org/10.3303/CET1651031

[16] Jamshidi, A., Hamzah, M. O., You, Z. "Performance of Warm Mix Asphalt containing Sasobit $₫$ : State-of-the-art", Construction and Building Materials, 38, pp. 530-553, 2013.

https://doi.org/10.1016/j.conbuildmat.2012.08.015

[17] Wasiuddin, N., Saha, R., King, Jr., W., Louay, M. "Effects of Temperature and Shear Rate on Viscosity of Sasobit $₫$-Modified Asphalt Binders", International Journal of Pavement Research and Technology, 5(6), pp. 369-378, 2012.

[18] Ghuzlan, K. A., Al Assi, M. O. "Sasobit-Modified Asphalt Binder Rheology", Journal of Materials in Civil Engineering, 29(9), Article number: 04017142, 2017.

https://doi.org/10.1061/(ASCE)MT.1943-5533.0001996
[19] European Committee for Standardization "BS EN 12591. Bitumen and bituminous binders. Specifications for paving grade bitumens", British Standards Institution, London, UK, 2009.

[20] European Committee for Standardization "BS EN 1426:2015 - TC Bitumen and bituminous binders - Determination of Bitumen and bituminous binders - Determination of needle penetration", British Standards Institution, London, UK, 2015.

[21] European Committee for Standardization "EN 1427:2015 Bitumen and bituminous binders - Determination of the softening point. Ring and Ball method", British Standards Institution, London, UK, 2015.

[22] Nassar, I. M., Kabel, K. I., Ibrahim, I. M. "Evaluation of the Effect of Waste Polystyrene on Performance of Asphalt Binder", ARPN Journal of Science and Technology, 2(10), pp. 927-935, 2012.

[23] Al-Hadidy, A. I., Tan, Y. "Effect of polyethylene on life of flexible pavements", Construction and Building Materials, 23(3), pp. 14561464, 2009.

https://doi.org/10.1016/j.conbuildmat.2008.07.004

[24] Marandi, S. M., Ghasemi, M. "Laboratory Studies of the Effect of Recycled Glass Powder Additive on the Properties of Polymer Modified Asphalt Binders", International Journal of Engineering, Transactions A: Basics, 26(10), pp. 1183-1190, 2013.

https://doi.org/10.5829/idosi.ije.2013.26.10a.08

[25] European Committee for Standardization "BS EN 13924-1:2015 Bitumen and bituminous binders - specifications for paving grade bitumens -Annex A Calculation of the penetration index, $\mathrm{I}_{\mathrm{p}}$ ", British Standards Institution, London, UK, 2015.

[26] European Committee for Standardization "BS EN 13302:2018 Bitumen and bituminous binders - Determination of dynamic viscosity of bituminous binder using a rotating spindle apparatus", British Standards Institution, London, UK, 2018.

[27] Weigel, S., Stephan, D. "The prediction of bitumen properties based on FTIR and multivariate analysis methods", Fuel, 208, pp. 655661, 2017. https://doi.org/10.1016/j.fuel.2017.07.048

[28] Lushinga, N., Cao, L., Dong, Z. "Effect of Silicone Oil on Dispersion and Low-Temperature Fracture Performance of Crumb Rubber Asphalt", Advances in Materials Science and Engineering, 2019, Article ID 8602562, 2019. https://doi.org/10.1155/2019/8602562

[29] AlHumaidan, F. S., Hauser, A., Rana, M. S., Lababidi, H. M. S., Behbehani, M. "Changes in asphaltene structure during thermal cracking of residual oils: XRD study", Fuel, 150, pp. 558-564, 2015. https://doi.org/10.1016/j.fuel.2015.02.076

[30] Mashaan, N. S., Ali, A. H., Karim, M. R., Abdelaziz, M. "Effect of crumb rubber concentration on the physical and rheological properties of rubberised bitumen binders", International Journal of the Physical Sciences, 6(4), pp. 684-690, 2011.

[31] Taherkhani, H., Afroozi, S. "The properties of nanosilica-modified asphalt cement", Petroleum Science and Technology, 34(15), pp. 1381-1386, 2016. https://doi.org/10.1080/10916466.2016.1205604

[32] Presti, D. L. "Recycled Tyre Rubber Modified Bitumens for road asphalt mixtures: A literature review", Construction and Building Materials, 49, pp. 863-881, 2013. https://doi.org/10.1016/j.conbuildmat.2013.09.007 
[33] Wang, H., You, Z., Mills-Beale, J., Hao, P. "Laboratory evaluation on high temperature viscosity and low temperature stiffness of asphalt binder with high percent scrap tire rubber", Construction and Building Materials, 26(1), pp. 583-590, 2012. https://doi.org/10.1016/j.conbuildmat.2011.06.061

[34] Zhao, G., Guo, P. "Workability of Sasobit Warm Mixture Asphalt", Energy Procedia, 16(B), pp. 1230-1236, 2012 https://doi.org/10.1016/j.egypro.2012.01.196

[35] Xiao, F., Amirkhanian, S., Wang, H., Hao, P. "Rheological property investigations for polymer and polyphosphoric acid modified asphalt binders at high temperatures", Construction and Building Materials, 64, pp. 316-323, 2014.

https://doi.org/10.1016/j.conbuildmat.2014.04.082

[36] Pyshyev, S., Gunka, V., Grytsenko, Y., Bratychak, M. "Polymer modified bitumen: Review", Chemistry and Chemical Technology, 10(4), pp. 631-636, 2016.

https://doi.org/10.23939/chcht10.04si.631
[37] Nivitha, M. R., Prasad, E., Krishnan, J. M. "Ageing in modified bitumen using FTIR spectroscopy", International Journal of Pavement Engineering, 17(7), pp. 565-577, 2016. https://doi.org/10.1080/10298436.2015.1007230

[38] Butt, A. A., Jelagin, D., Tasdemir, Y., Birgisson, B. "The effect of wax modification on the performance of mastic asphalt", International Journal of Pavement Research and Technology, 3(2), pp. 86-95, 2010. https://doi.org/10.6135/ijprt.org.tw/2010.3(2).86

[39] Khordehbinan, M., Kaymanesh, M. R. "Chemical analysis and middle-low temperature functional of waste polybutadiene rubber polymer modified bitumen", Petroleum Science and Technology, 38(1), pp. $8-17,2020$ https://doi.org/10.1080/10916466.2019.1608237

[40] Geçkil, T. "Physical, Chemical, Microstructural and Rheological Properties of Reactive Terpolymer-Modified Bitumen", Materials, 12(6), Article number: 921, 2019. https://doi.org/10.3390/ma12060921 